\section{No biotechnology bandwagon}

OVER the past ten years, stimulated by worldwide enthusiasm for biotechnology, Finland's scientific community has been laying the groundwork for a genetic engineering industry. But as these efforts bear fruit, the wind is being taken out of its sails by a virtual absence of risk capital and apparent lack of interest from industry in radical new production processes.

The situation has been a major source of frustration for scientists such as Helena Mäkelä, professor of infectious diseases at the National Public Health Institute. Mäkelä chaired a committee set up by the Finnish Academy in the mid-1980s which designed a five-year programme adopted by the Ministry of Education to boost biotechnology in Finland.

The academic part of the programme was highly successful. Almost 70 PhDs have been produced in the disciplines considered essential for the health of a successful biotechnology industry. Four university-based biotechnology centres have been created with special funds from the Ministry of Education, based on research at the universities of Helsinki, Oulu, Turku and Kuopio.

But industrial enthusiasm for biotechnology has been less forthcoming, and has cooled even further with the current recession. "In the academy, it has become clear that industry has not developed an interest in biotechnology as fast as we had expected, and that many of the scientists we have trained up will be left without a job", says Mäkelä.

Generous government funding for the university-based centres, combined with efforts to ensure that each is plugged into international research networks, has ensured that the standard of research and

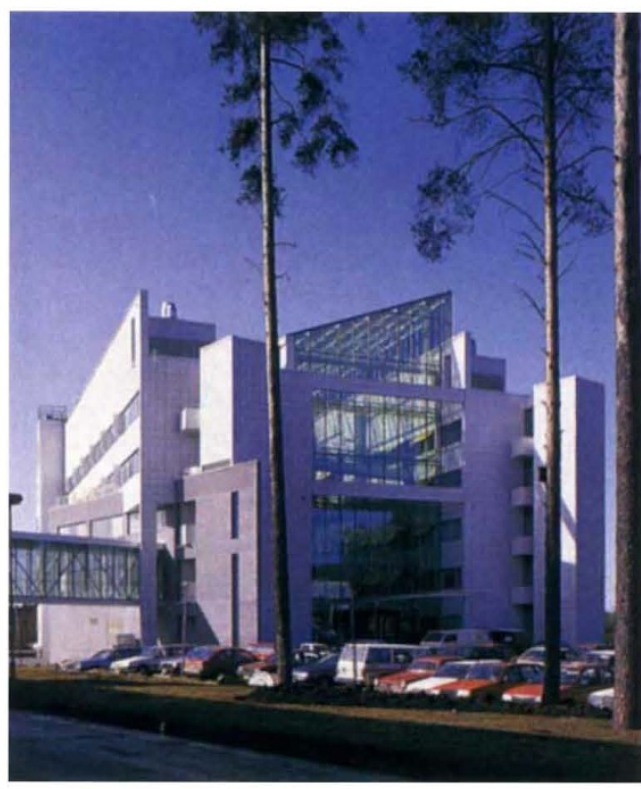

The new Medipolis Centre at Oulu, housing start-up biotech companies. training has been high. The Biocenter Oulu, for example, which was established in 1986 and brings together project groups based in a number of different rescarch departments at the University of Oulu, already accounts for one third of the PhDs produced by the university.

At the University of Helsinki, more than a hundred people now work at the Institute of Biotechnology, set up in 1989 as a successor to the university's Recombinant DNA Laboratory, which was one of the first groups to carry out genetic engineering research in Finland. "Over the past ten years, a molecular biology culture, based on four centres each now enjoying an international reputation, has been developed in this country almost from scratch", says the institute's director, Mart Saarma.

The picture in terms of new products is not all gloomy. For example, scientists at the Biotechnical Laboratory of Finland's National Technology Centre have developed a technique for bleaching wood-pulp without the use of chlorine which is steadily gaining acceptance in the country's paper and pulp industry. Research carried out by Kari Kivirikko at the University of Oulu has led to the development of a new drug for fibrosis, clinical trials of which are now being carried out by Hoechst in Germany.

So far, however, such success stories have been the exception rather than the rule. The traditional conservatism of Finnish industry - particularly those, such as the paper and pulp industry and the brewing industry, in which the government had been hoping biotechnology would make its mark - has made it slow to accept the new techniques.

Obtaining the venture capital that entrepreneurs in other countries have used to build up small biotechnology companies has also proved difficult. "We have a very exciting research environment, but the problem in this country is a lack of venture capital", says Karl Tryggvason, professor of biochemistry at the University of Oulo and scientific director of the Biocenter.

On top of all this, there have been a number of setbacks that have increased the nervousness of potential investors. There was, for example, the experience of Genesit, a small biotechnology company set up in the mid-1980s with funding from the government, the Finnish Industrial Fund for Technical Development (SITRA) and seven large Finnish corporations to explore ways of exploiting the use of Bacillus subtilis. Genesit was widely seen as Finland's entry ticket into the brave new world of venture-capital- based biotechnology. But it eventually folded after encountering technical difficulties in developing marketable processes.

Equally embarrassing has been the recent collapse of attempts of another biotechnology company, Pro Vivo, to establish a company, called Arctic Point, to produce food products based on blood extracts. Pro Vivo bought the technology from VTT, and persuaded a group of investors to put up Fmk25 million to build a new factory for producing sausages using globin extracted from blood as a substitute for milk protein.

According to Ralf Lundell, the managing director of Pro Novo, the project failed when it was discovered that the globin did not bind to the fats in the sausages as well as the conventional forms of protein. The companies responsible for marketing the sausages were not prepared to change the basic recipe to increase the amount of lean meat to compensate for this, he says. As a result, Arctic Point, widely touted as one of the successes of Finnish biotechnology, went into bankruptcy last month.

Now, even companies with an established track record in developing novel approaches to biotechnological processes are cutting back on long-term work to focus on more product-oriented objectives. Finland's state-owned brewery Alko, for example, which for the past 10 years has had a team of about 70 researchers working on the development of new vector systems such as Trichoderma for producing cellulase enzymes and other products, has decided that it wants its scientists to work more closely than in the past with its business units.

"We are focusing our work on the strategic interests of our business decisions, and our research goals are becoming more clearly defined", says Matti Korhola, director of research at Alko. In the process, the company will be reducing the size of its molecular biology research team by about 10 per cent. "We are maintaining a fairly strong centralized R\&D function in the research laboratories, but we also aim at faster utilization and application of our results", says Korhola.

In the pharmaceutical field, several companies are turning away from genetic engineering, wary of the time needed to turn bright ideas into products, and refocusing on more conventional ways of producing new drugs.

Despite setbacks and retrenchment, however, many scientists remain optimistic about the future. "Over the past ten years, the number of people able to master the basic techniques of modern biotechnology have increased exponentially, and we now have the human capacity that was missing when we started," says Leevi Kääriäninen, research director at the Institute of Biotechnology in Helsinki. "The question now is how to keep the faith." 